\title{
Against the speaker-intention theory of demonstratives
}

\author{
Christopher Gauker ${ }^{1}(\mathbb{D})$
}

Published online: 12 September 2018

(C) The Author(s) 2018

\begin{abstract}
It is commonly supposed that an utterance of a demonstrative, such as "that", refers to a given object only if the speaker intends it to refer to that object. This paper poses three challenges to this theory. First, the theory threatens to beg the question by defining the content of the speaker's intention in terms of reference. Second, the theory makes psychologically implausible demands on the speaker. Third, the theory entails that there can be no demonstratives in thought.
\end{abstract}

Keywords Demonstratives · Reference · Speaker's intention · Context-relativity

\section{The dirty fork}

Imagine that we are seated at a table in a restaurant. I look at the fork next to my plate. I point at it with my finger. I utter, "That is dirty". However, as I speak, I am thinking of the fork in front of the person sitting to my left. A moment earlier I had looked at it and seen that it was dirty. My glance to my own fork and my gesture with my finger were entirely accidental. I did not mean to draw attention to the fork in front of me. What I intended to speak of —intended to refer to-was the dirty fork in front of the person to my left. The fork in front of me is perfectly clean.

Is my utterance of the sentence "That is dirty" true? False? Neither true nor false? It is false if my utterance of "that" refers to the fork in front of me, true if it refers to the fork to my left, and neither if it does not succeed in referring at all. Many contemporary authors answer either "true" or "neither". An utterance of "that", they say, can only refer to the object that the speaker intends to refer to. If

Christopher Gauker

christopher.gauker@sbg.ac.at

1 Department of Philosophy, Faculty of Cultural and Social Sciences, University of Salzburg,

Franziskanergasse 1, 5020 Salzburg, Austria 
intending to refer is enough to secure a reference, then my utterance of "that" refers to the dirty fork on my left, and my utterance of the sentence "That is dirty" is true. If additional conditions have to be fulfilled, such as that the hearer has to be in a position to recognize my intention, then my utterance of "that" may fail to refer to anything and in that case my utterance of the sentence "That is dirty" will be neither true nor false. The one possibility that is ruled out, according to these authors, is that my utterance of "that" refers to the fork in front of me and my utterance of the whole sentence is false.

This paper will be exclusively an "intervention" in the sense that that term has recently acquired in philosophy. I want to argue against a number of authors that the following theory of demonstrative reference is false:

The speaker-intention theory of demonstrative reference: An object $o$ is the reference of an utterance of "that" only if $o$ is what the speaker intends to refer to in making that utterance of "that".

The speaker-intention theory of demonstratives is usually treated as a commonplace requiring no defense at all (although there have occasionally been critics, a prominent case in point being Wettstein 1984). Authors who take it as a topic for discussion often hold (as we will see) that the reference of a demonstrative must meet other conditions in addition. However, I will not be concerned with whether the addition of further conditions might improve the theory. The target of my critique will be the claim that the speaker's intention is in this way even as much as a necessary condition on the reference of a demonstrative.

First, I will lay down what I take to be an appropriate framework in which to address the issue. Next, I will examine some of the writings of proponents of the speaker-intention theory, because I think there are some additional errors mixed in that need to be cleared away before we focus on the main issue. Finally, I will offer three arguments against the speaker-intention theory: First, it threatens to beg the question, because no non-question-begging account of the content of the pertinent intention is forthcoming. Second, it places psychologically implausible demands on the intentions of the speaker. Third, it places excessive burdens on an account of demonstrative thought. For simplicity I will confine the discussion to so-called bare demonstratives such as "this" and "that". Bare demonstratives contrast with complex demonstratives, which include a noun phrase, as in "that lazy cat" or "this unremarkable automobile". I will not in this paper try to develop an alternative theory of demonstrative reference. ${ }^{1}$

Nothing I write here will qualify as a refutation of the speaker-intention theory. My objections amount to challenges. I cannot show that no amount of additional theory on behalf of the speaker-intention theorist will succeed in meeting those challenges. But my three challenges nonetheless qualify as a critique of the speakerintention theory, because I expect that some readers will be persuaded that these challenges are probably insurmountable or that it is best to look elsewhere for a theory of the reference of demonstratives.

\footnotetext{
1 I have made a start on that project in Gauker (2008).
} 


\section{The framework}

First, I need to clarify the kind of reference at issue, because, of course, the word is used in various ways. The current topic is not so much what might be called speaker's reference. It is, rather, what we might call semantic reference. It is the kind of reference in terms of which we formulate the truth conditions of utterances of sentences.

When someone says, "I was referring to..." or when someone asks, "Who were you referring to when you said...?", then what is at issue is what I will call speaker's reference, without trying to define this notion any more precisely. No doubt what is at issue in such cases concerns what the speaker had in mind in some sense. I do not think we should just assume that this is exclusively a matter of what the speaker intends apart from semantic reference (a term I will explain next). One possibility is that the issue in such cases is what the speaker took him- or herself to be referring to in the semantic sense. But in this paper I am not going to examine that question any further.

My topic is exclusively the reference we need to attribute to an utterance of "that" in order to specify the conditions under which the utterance of a sentence containing that utterance of "that" is true, which is what I call semantic reference. (Alternatively, we could characterize semantic reference in terms of the proposition expressed by the utterance, but I will approach the matter in terms of truth conditions.) For instance, if someone utters the sentence "That is dirty", then the utterance of that sentence is true if and only if the thing that that utterance of "that" refers to has the property that is the reference of that utterance of "is dirty". Similarly, if Betty utters the sentence, "If Jack brought that, then it's stolen", then her utterance is true if and only if: if Jack brought the object that is the reference of her utterance of "that", then the object that is the reference of her utterance of "that" is stolen. The topic of this paper is the kind of reference we speak of in specifying truth conditions in this way.

Toward formulating the issue still more precisely, I need to set down a number of background assumptions. The first is simply that we need to distinguish between sentences and utterances of sentences. A sentence is a repeatable type, and an utterance is a temporally, spatially located instance of that type. (These are reminders, not definitions.) For example, a single sentence, "Everyone is ready," might be uttered just before the chorus starts to sing, and might be uttered again just before the group parachute jump.

Sentences, I will suppose, are true or false only relative to a context. For instance, "Everyone is ready" is true relative to a context if and only if the domain of discourse for the context includes only people who have the property that the context specifies for "ready". ${ }^{2}$ Likewise, we will need to countenance contextrelativity in order to formulate the semantics of adjectives such as "small" and modal operators such as "might". The term "context" can be used either to refer to

\footnotetext{
${ }^{2}$ Exactly how contexts should be understood and how the context-relativity should be understood in order to capture the context-relativity of quantifiers and incomplete predicates (such as "ready") is a complex topic in its own right. What I have said here is not meant to resolve any of these issues. For my own contributions to these debates, see Gauker (2010) and Gauker (2012).
} 
a formal structure that assigns values to various parameters and in terms of which the truth conditions of sentences relative to contexts can be precisely defined, or it can be used to refer to the concrete situation of which an utterance is a part. I will use the term exclusively in the first way, to refer to a formal structure.

Given that a context is a formal structure that we can define, a semantic theory for a language can take the form of recursive definition of truth-relative-to-acontext. For every sentence $S$ and every context $c$, the theory should generate a biconditional of the form, " $S$ is true in context $c$ if and only if..." (where the righthand-side is filled in using a metalanguage that is taken to be understood). Perhaps this is an oversimplification. Perhaps we will need to distinguish between the context and other parameters of interpretation, such as possible world and interpretation (in the sense of an assignment of an extension to each non-logical term). Or perhaps not; perhaps we can contrive to build all of the necessary parameters into the context. For present purposes I am going to ignore the possible complications and just assume that context is the only parameter we need to consider. On this assumption, we can look forward to defining logical properties for sentences of the language in question in terms of truth-in-a-context. For instance, we can say that an argument (in the sense of premises and conclusion) is logically valid if and only if, for each context $c$, if the premises are all true in $c$, then so is the conclusion.

So, sentences are true or false only relative to a context. Utterances, by contrast, are true or false simpliciter. Utterances take place in situations. Exactly how to define situations is another question that I will not take up here, but, roughly speaking, a situation is a collection of concrete objects and events. Some situations include, as parts, utterances of sentences. The situation in which an utterance is embedded might include the speaker, the audience, the thoughts of the speaker of the utterance, the objects and events that the speaker and audience may be talking about, etc. We do not need to relativize the truth of utterances to situations, because there is no need to consider what the truth value of a given utterance would be if we, so to speak, cut it out of the situation that it actually belongs to, and pasted it into another. (In thinking about the modal properties of utterances, we might want to think about a single utterance in different situations, but the modal properties of utterances have no more bearing on semantics than the modal properties of any other arbitrarily chosen thing.)

There is a tight relation between the truth (simpliciter) of utterances and the truthin-a-context of sentences. For each utterance there should be a context that pertains to the utterance in the sense that that is the context we need to refer to in specifying the truth conditions of the utterance. More precisely, a context pertains to an utterance of a sentence if and only if the values of the various parameters specified by that context are those values that are relevant for purposes of evaluating the utterance. Then we can define utterance truth in terms of sentence truth-in-a-context, thus:

An utterance of a sentence $S$ is true (simpliciter) if and only if $S$ is true relative to the context that pertains to the utterance.

For example, suppose that the context that pertains to an utterance of "Everyone is ready" is one in which the domain of discourse is the set of parachuters on a certain 
airplane, and the activity specified for "ready" is jumping from the airplane. Then that utterance will be true (simpliciter) if and only if all of the parachuters on the airplane are ready to jump from it.

While the structure of contexts and the conditions under which sentences are true in a context is something we should expect to be able to define quite precisely, we should not expect comparable precision in the definition of the pertaining relation. Somehow the features of the situation in which the utterance takes place will determine which context pertains to it. As we will see, the speaker-intention theory can be usefully formulated as part of an explanation of the pertaining relation.

A demonstrative expression such as "that" can be used to refer to different things on different occasions. In the framework of a context-relative semantics, there are a couple of ways to think about this variability. One way might be to suppose that different contexts assign different referents to the abstract expression-type "that". 3 If we go this route, then the speaker-intention theory, as I formulated it in the introduction, can be characterized as a consequence of the following constraint on the pertaining relation: A context $c$ pertains to an utterance $u$ of a sentence $s$ containing an utterance $t$ of "that" only if the object that $c$ assigns to the word "that" is the object that the utterer of $u$ intended to refer to in uttering $t$.

However, there are problems with this way of thinking about the variability of the reference of "that". These have to do with the fact that we sometimes want to allow two or more occurrences of "that" in a single sentence to refer to distinct objects. We want to allow a reading of "That is ripe, but that is not ripe" on which it is literally true in a single context. But we also want to allow a reading of the argument, "That is ripe; therefore, that is ripe" (with premise and conclusion being the very same sentence), on which it is valid. The challenge is then to explain what kind of thing a reading of a sentence might be such that both of these results hold. A possible solution is to suppose that distinct occurrences of "that" may sometimes be occurrences of different lexical items, taking potentially distinct interpretations, and may sometimes be occurrences of the same lexical item, requiring the same interpretation. ${ }^{4}$ If we take this approach, the speaker-intention theory could be formulated as a condition on the individuation of lexical items. We can formulate it just as I did in the introduction, but then we can go on to clarify that two utterances of "that" are utterances of the same lexical item only if (we will not say "if and only if") what the speaker of the one intends to refer to is the same as what the speaker of the other intends to refer to.

My hope, and expectation, is that proponents of the speaker-intention theory will be able to translate into their own favored vocabulary the terms that I have introduced here, including context, situation and pertaining, and will be able to locate their position within the space of possibilities that I have outlined in this section.

\footnotetext{
${ }^{3}$ Kaplan considers this theory in Kaplan (1989), but it is not his main theory. One source in which it is clearly adopted is Larson and Segal (1995).

${ }^{4}$ For elaboration on the arguments and ideas in this paragraph, see Gauker (2015).
} 


\section{Some examples of the speaker-intention theory}

In order to demonstrate that I am not attacking a strawman and in order to isolate the key point that I am attacking, it will be useful to examine the words of a couple of proponents of the speaker-intention theory. A particularly clear example of the speaker-intention theory is Jeffrey C. King's theory of demonstratives in his 2014. King writes:

So I suggest we say that the value of a use of a demonstrative in a context is that object o that meets the following two conditions: 1) the speaker intends o to be the value; and 2) a competent, attentive, reasonable hearer would take o to be the object that the speaker intends to be the value. (King 2014, p. 225)

The first condition in this claim is the speaker-intention theory. The second condition goes beyond the speaker-intention theory. King acknowledges that someone might disagree, but otherwise he just takes the speaker-intention theory for granted. The point of his paper is to defend the second condition. King argues that it is needed because the speaker can be required to speak understandably. Similar endorsements of the speaker-intention theory can be found in Stokke (2010) and Speaks (2016). ${ }^{5}$

Besides its commitment to the speaker-intention theory, which I will criticize in the bulk of this essay, King's theory contains another, less important error. That is its relativization of the "use of a demonstrative" to a context. I assume that what King calls the use of a demonstrative is what I have called an utterance of a demonstrative. I cannot take for granted that what King is calling a context is what I have called a context. Perhaps what he is calling a context is something more like what I have called a situation. Regardless of which way we are thinking of contexts, there is no apparent reason to relativize the reference of an utterance of a demonstrative to a context. There is not any sense in which various different formal contexts may pertain to the utterance of a demonstrative. And we have no reason to consider the reference of an utterance of a demonstrative in situations other than the one in which it occurs. ${ }^{6}$

King takes himself to explaining what it takes for an occurrence of a demonstrative to refer to something. Richard G. Heck, Jr., by contrast, rejects the question. He writes,

If the members of the audience are interested in communicating successfully with the speaker, then the question they must ask themselves is therefore: Which object did the speaker expect I would understand her to be speaking about? Or if you like: To which object did the speaker mean to refer? (Heck 2014, 342)

\footnotetext{
5 Speaks (2016) too accepts the speaker-intention theory without argument, but he criticizes King's second condition. Stokke's paper is earlier than King's, but his commitment to the speaker-intention theory is not quite as evident on the surface. What Stokke says is that we can model the speaker's intention as a function from the indices that are used to differentiate different occurrences of "that" to referents (2010, p. 393).

6 Speaks (2016), like King (2014), unaccountably relativizes uses of demonstratives to contexts, but Speaks (2017) does not do that (but instead relativizes demonstratives, considered as expression types, to contexts).
} 
Off hand, this might look like an endorsement of the speaker-intention theory. But then Heck continues, thus:

The question-assuming that it is a different question-is very much not: To what did the uttered demonstrative refer? If the answers to the two questions can come apart, why should you, as a party to the conversation, care whether the "objective" referent diverges from the one the speaker intended? (Heck 2014, 342)

In short, the only question of interest is what the speaker intends to refer to, and there is no further question about what the speaker's utterance of "that" refers to. Jonas Akerman, writing at about the same time as Heck, likewise denies that we need to countenance a reference relation for utterances of demonstratives (Åkerman 2015).

This rejection of the question, I contend, is a mistake. There seems to be a very clear answer to Heck's question, "Why should you care about the objective reference?" Namely, we want an account of what it is that interlocutors know about their language that enables them to communicate by means of it. An account of what interlocutors know about the reference of utterances of "that" would be part of our account of that knowledge. If like Heck, in the first quotation, you think that hearers are only interested in the content of the speaker's thought, then you should say that hearers have no reason to take the reference of "that" to be object $o$ unless they take $o$ to be that which the speaker intended to refer to. But even in that case, you should still say that a hearer assigns an interpretation to the speaker's utterance of a sentence as a means of identifying the whole thought that the speaker intends to express with the sentence that contains it and that, as part of the process of interpreting an utterance of a whole sentence, the hearer assigns an interpretation to an utterance of "that".

Moreover, we should care about the so-called objective reference for purposes of formulating the logical properties of sentences containing demonstratives. We would like to say that the argument, "That is ripe; therefore, something is ripe" is logically valid. So there needs to be some kind of parameter such that we can say that for each value of that parameter relative to which "That is ripe" is true, "Something is ripe" is true relative to that value of that parameter as well. When a given value of the parameter is the one that pertains to a given utterance of "that", then what "that" refers to relative to that value will be what Heck calls the objective reference of "that". For instance, as I suggested in Sect. 2, the relevant parameter might be a context variable. The reference of an occurrence of "that" will be what the expression-type "that" refers to relative to the context that pertains to it.

\section{First objection: the threat of begging the question}

My first objection to the speaker-intention theory is that it threatens to beg the question. More precisely, the objection has two parts. The first part is that the theory at least threatens to beg the question in the way it formulates the content of the relevant speaker intention. The second part of the objection runs thus: If question- 
begging can be avoided by substituting a non-question-begging account of the content of the relevant speaker intention, then the theory is liable to be subject to counterexamples.

The speaker-intention theory does not immediately beg the question. The content of the pertinent intention is described thus: to refer to object $o$ in uttering "that". Referring in this sense is supposed to be an act of the speaker. It is not a semantic relation of reference between an utterance and an object. So it is open to an advocate of the speaker-intention theory to hold that the nature of this act can be explicated without circling back to the semantic relation that is supposed to be explained. But how? It is in answering this question, that the theory is liable, i.e., threatens, to beg the question. That is because a prima facie plausible answer is the following: The speaker intends to use "that" to refer to an object $o$ if and only if the speaker intends to use "that" in such a way that his or her utterance of "that" does refer to $o$. If we explain the content of the speaker's intention in this way, then we come straight back to the question we were supposed to be answering: What does it mean to say that an utterance of "that" refers to a given object? The speaker-intention theory threatens to beg the question because one plausible account of the content of the speaker's intention leads in a circle, that is, is question-begging, and apart from this plausible account, it is not obvious what the content of the speaker's intention is supposed to be.

For various reasons this danger of begging the question may fail to stand out. King does not say that the speaker intends $o$ to be "the reference" of a demonstrative. He says that the speaker intends $o$ to be "the value" of the use of a demonstrative (see the quotation in Sect. 3, above). King does not explain, but we can assume that the value of an utterance of expression is that which that utterance contributes to the truth conditions of the sentence utterance of which it is part. In other words, the value in question is the semantic value, that is, the reference. Or the danger of begging the question might be concealed if it is said that the reference of an utterance of "that" is what the speaker intends to be talking about. (See Heck's use of the phrase "speaking about" in the first quotation from him in Sect. 3, above.) When we utter a demonstrative, there may be many things we are talking about in some sense, for instance, the general topic of conversation, as well as the specific reference of the demonstrative. The kind of talking about that might define the reference of a demonstrative is using a demonstrative to refer to a thing. But again we can ask, how are we to understand the content of that intention if not in the circular way as the intention to use a demonstrative that refers to that thing?

As for the second part of the objection, there are various non-question-begging accounts of the content of the speaker intention that we could try in place of the question-begging one. So we might say: a speaker refers to $o$ in uttering "that" only if the speaker intends to draw the hearer's attention to o by uttering "that". The trouble is that that answer is subject to clear counterexamples. The speaker may very well know that the hearer's attention is already focused on the referent of "that" and intend to draw the hearer's attention to something else. Suppose that A is holding a knife and looking at it as if to decide whether it is suitable as a weapon. But $\mathrm{B}$ sees that there is a big man with a gun coming around the corner; the knife will not protect A from him; it would be better for A to run. So B says, "That will 
not help you against the big guy over there with a gun." So the speaker intends to draw the hearer's attention to the big man with a gun by uttering a sentence in which "that" refers to the knife that the hearer is holding. The referent is not what the speaker intends to draw the hearer's attention to.

A lot of attempts to find a non-question-begging account of the speaker's intention end up threatening to beg the question again. For instance, we might try this:

The speaker intends utterance $u$ of "that" to refer to object $o$ if and only if the speaker intends the hearer to assign $o$ to $u$ for purposes of determining the truth conditions of the sentence-token of which $u$ is a part.

The trouble with this explication is that it leaves unclear what it means to assign something for purposes of determining truth conditions. In principle this could mean various things. In some sense of "assign", I could assign Richard Feynman to the "that" in "That is a muon" for purposes of determining the truth conditions of that sentence, because I think he will tell me what a muon is. Obviously that's not the kind of assigning that is intended in this definition. But what kind of assigning is intended then? A good answer, but one that leads in circles, is this: assigning to each utterance what it really refers to.

Or we might try to define the content of the speaker's intention in terms of the truth conditions for the complete utterance of a sentence. For example, we might say that the speaker intends the utterance of "that" in "That is ripe" to refer to the persimmon in the lower left-hand corner of the box if and only if the speaker intends "That is ripe" to be true if and only if the persimmon in the lower left-hand corner of the box is ripe. The main trouble with this approach is that it does not generalize to the case of sentences containing more than one occurrence of "that". Suppose we try it for the sentence, "That is more ripe than that", thus:

The speaker intends the first utterance of "that" in an utterance of "That is more ripe than that" to refer to the persimmon in the lower left-hand corner of the box and intends the second utterance of "that" in that utterance to refer to the persimmon in the upper right-hand corner if and only if: the speaker intends "That is more ripe than that" to be true if and only if the persimmon in the lower left-hand corner is more ripe than the persimmon in the upper-right hand corner.

The trouble with this analysis is that the right-hand side of the biconditional does not say anything about which persimmon goes with which occurrence of "that". So the right-hand side is not a sufficient condition for the left-hand side.

Perhaps we could avoid all reference to truth conditions and rely instead on the idea that utterances of whole sentences express whole thoughts and that there is a certain correspondence between the structure of the utterance of the sentence and the structure of the content of the thought expressed. So if I utter the sentence "That is bigger than that", then I might thereby express a thought having the content $o_{1}$ is bigger than $\mathrm{o}_{2}$, and in that case $o_{1}$ corresponds to the first utterance of "that" in my utterance of the sentence and $o_{2}$ corresponds to the second utterance of "that" in my utterance of the sentence. Assuming that we could spell out the nature of the 
structural correspondence adequately, we could say: A speaker intends to refer to an object $o$ in making utterance $u$ of "that" if and only if $o$ is the component that corresponds to $u$ in the content of the thought that the speaker expresses by uttering the sentence containing $u$. The trouble is that this leaves us needing an account of the expression of thoughts through utterances. Somehow the content of the thought expressed has to be grounded in the semantics of the sentence uttered. In particular, we will need an account of the reference relation between demonstratives and their referents, which the speaker-intention theory aimed to provide.

Another reply begins with the observation that everyone who possesses a language understands in a practical way what reference is, so that it can be said that he or she grasps of the concept reference. Every speaker knows, of some proper names, who they refer to. Every speaker knows, of some predicates, such as "est un chien", what they refer to, such as the property of being a dog. It is this grasp of the concept reference that speakers deploy when they intend to use a demonstrative to refer to something, and it is to this grasp of the concept reference that we are appealing when we state the speaker-intention theory of demonstratives. On the contrary, in the case of the demonstrative "that", a speaker is free to use it (is not constrained by linguistic convention from using it) to refer to different things on different occasions. In the case of proper names and predicates, a speaker is not in the same way free to use them to refer to different things on different occasions. The speaker-intention theory is intended to provide a theory of reference for a kind of expression to which the model of proper names and predicates does not well apply. So a speaker's grasp of the concept of reference in connection with proper names and predicates provides no adequate model by means of which we might understand the speaker's intention to refer by means of a demonstrative. ${ }^{7}$

None of this shows that there is any mystery in someone's intending to use an utterance of "that" to refer to something. Given a good account of what it is for an utterance of "that" to refer to something (which I am not offering here), we can say that a speaker intends to use an utterance of "that" to refer to $o$ if and only if the speaker intends to utter "that" in such a way, in such circumstances, that it refers to $o$. That explanation of the content of the speaker's intention is fine, as far as it goes. But it is not an explanation that the speaker-intention theory can use without begging the question. I am not aware of any non-question-begging account of the content of the speaker's intention that the speaker-intention theory can use that is not subject to counterexamples.

\footnotetext{
7 In an earlier paper (Gauker 2008) I briefly stated the objection of begging the question. Lewerentz and Marschall (2018) have published a critique of that passage. My answer to the objection in Sect. 5 of their paper is my observation in the present paragraph that the reference of other kinds of terms does not provide an adequate model for the reference of demonstratives. My answer to the objection in Sect. 4 of their paper is just to reiterate the point that apart from an account of the content of the speaker's intention, the speaker-intention theory threatens to beg the question. In Sect. 3 of their paper, Lewerentz and Marschall argue that explicating the reference relation falls both outside of semantics and outside of metasemantics, and so a proponent of the speaker-intention theory owes no answer to my objection. I do not understand how this demarcation of fields of study shields the speaker-intention theory from criticism.
} 


\section{Second objection: psychological implausibility}

We need to distinguish between two questions:

The constitutive question: What is the relation of reference between an utterance of a demonstrative and the thing it refers to?

The epistemological question: What may we conclude about what a given utterance of a demonstrative refers to?

We must acknowledge that on occasion an utterance of a demonstrative might refer to a given object even though no one (other than, perhaps, the speaker) is in a position to find this out or even though the best supported hypothesis is that it refers to something else. So not only are the two questions distinct in intension, but also the answers are distinct in extension.

On the other hand, the questions are not as distinct as the questions "What are the truths of mathematics?" and "What can we conclude to be mathematically true?", or as distinct as the questions, "How many mice were born in the year 8000 BC?" and "What may we conclude about the number of mice born in the year 8000 BC?" Language is designed for communication (through natural selection and cultural processes resembling natural selection). So we should expect that normally (in both a statistical and a functional sense) the meanings of words will be known to the speakers of a language. (Perhaps exceptions must be made for names of historical figures or natural kind terms.) In particular, we should expect that normally the reference of an utterance of a demonstrative will be discoverable by members of the audience to whom the utterance is directed. Even King seems to acknowledge as much, which is why he adds condition (2) to his account of demonstrative reference (see the quotation in Sect. 3 above).

So it is fair to hold a proponent of the speaker-intention theory responsible for showing that there could be a reliable method by which audiences could normally identify the reference of a demonstrative. Since, by the speaker-intention theory, the speaker's intention to refer is at least partially constitutive of the reference of the utterance of a demonstrative, that method must be equally a method of discovering the speaker's intention to refer. Even if hearers are not expected to think of the reference of an utterance of a demonstrative as the object of the speaker's referential intention, still, since it always $i s$ that, a reliable method for discovering the referent has to be de facto a reliable method for discovering the speaker's intention to refer.

I will not argue that the only possible basis for the hearer's inference would be an independent identification of the reference of the speaker's utterance of a demonstrative. Rather, I will argue that if we compare two pictures of the epistemological relation between a speaker's referential intention and the reference of a demonstrative, one compatible with the speaker-intention theory and one opposed to it, then the one opposed is the psychologically more plausible. For present purposes, I will pretend that a proponent of the speaker-intention theory can explicate the content of the pertinent intention without circularity. 
When a hearer attempts to understand what a speaker's utterance of a demonstrative refers to, the hearer will have to make inferences from what he or she can observe. Three broad categories of observation that may be relevant are: (1) Observations of the rest of the discourse to which the speaker's utterance belongs (which may include contributions by other speakers), (2) observations of the speaker's nonlinguistic behavior, and (3) observations of what is going on in the environment in which the conversation takes place (including the nonlinguistic behavior of other interlocutors). Let us call the objects of these observations the external factors.

A proponent of the speaker-intention theory will conceive of the epistemological relevance of the external factors in different ways than his or her opponent will. A proponent of the speaker-intention theory will conceive of the hearer as relying on these external factors in order to identify the speaker's referential intention. The hearer will be supposed to infer the reference of a speaker's utterance of a demonstrative (which the hearer needs to do in order to plug it into an interpretation of the speaker's utterance of a whole sentence) from the speaker's intention in accordance with the speaker-intention theory. Call this inference from the speaker's referential intention to the reference of the speaker's utterance of a demonstrative the mind-to-meaning inference. An opponent of the speaker-intention theory, in contrast, will conceive of the hearer as relying on the external factors in order to first infer the reference of the speaker's utterance of a demonstrative, that is, without passing through an identification of the speaker's referential intention. Then if the hearer has a reason to take an interest in the speaker's intention, the hearer may use his or her independent identification of the reference of the speaker's utterance of a demonstrative to infer the speaker's intention. When the hearer does take an interest in the speaker's intention, the hearer will normally, but not always, infer that the speaker intended to refer to that to which the speaker's utterance of a demonstrative does refer. Call this the meaning-to-mind inference.

The question I now want to consider is this: What is more plausible from a psychological point of view: That interlocutors engage in a mind-to-meaning inference? Or that they engage in a meaning-to-mind inference? I will try to show that the mind-to-meaning inference makes much stronger demands than the meaning-to-mind inference and that, consequently, it is psychologically less plausible that interlocutors actually undertake a mind-to-meaning inference than that they undertake a meaning-to-mind inference. The crucial difference lies not in the demands that the mind-to-meaning inference places on the hearer but in those it makes on the speaker.

A basic assumption underlying my argument will be that communication by means of a shared language requires that the interlocutors conform to certain rules or guidelines that specify the obligations of an interlocutor in the role of speaker and specify the obligations of an interlocutor in the role of hearer. These include rules concerning what speakers ought to do in order to be understandable and what hearers ought to do in order to understand. I do not assume that these are rules that interlocutors are conscious of or which are inscribed in their brains. Rather, the language machine in each interlocutor's brain may be so designed (by natural selection and enculturation) as to normally maintain conformity to these rules. 
What rules would characterize the thought of interlocutors in the use of demonstratives if hearers employed the meaning-to-mind inference (as opponents of the speaker-intention theory will suppose)? The answer would seem to be the following:

The hearer's rule (meaning-to-mind version): Figure out what the speaker's utterance of "that" refers to (and then, optionally, infer that the speaker intended to refer to that).

The speaker's rule (meaning-to-mind version): Where $o$ is the thing your utterance of "that" is to refer to, utter "that" in such a way, under such circumstances, that the utterance of it refers to $o$.

In the hearer's rule, inferring the speaker's intention is optional, because in most cases we only need to know what the speaker has said. There is a reason to think about the speaker's intention only if something specific happens that raises a doubt about whether the speaker meant what he or she said. It is important that the speaker's rule does not say anything about what is expected of the hearer. The speaker may have an obligation to facilitate the hearer's adherence to the hearer's rule, but in light of the hearer's rule, the speaker can do that just by uttering "that" in such a way, under such circumstances, that it really does refer to the thing to be referred to.

The protasis in the meaning-to-mind version of the speaker's rule ("Where $o$ is the thing your utterance of 'that' is to refer to") can be understood as alluding to the speaker's intention in that it speaks of what is to be rather than of what is. But it does not refer to a speaker's intention conceived as something that might determine or constrain the reference of an utterance of a demonstrative. It is not assumed that the reference of a demonstrative is determined, even in part, by the speaker's intention; rather, it is assumed that the speaker can have an intention concerning the reference that the demonstrative he or she utters will have. The speaker can have an intention toward this, without the intention's being determinative, just as one can have an intention regarding the long-term effects of one's actions, without those long-term effects being produced at will. Since we are not assuming that speakers have to consciously or even deliberately obey the rules, the supposition that this is a rule that governs discourse does not imply that speakers in any sense reflect on their own intentions in speaking, at most that they have them.

Next, what rules would characterize the thought of interlocutors in the use of demonstratives if hearers employed the mind-to-meaning inference (as proponents of the speaker-intention theory will suppose)? Here the pertinent rules would seem to be these:

The hearer's rule (mind-to-meaning version): Figure out what the speaker intended to refer to in uttering "that" (and then, optionally, infer that the speaker's utterance of "that" referred to that).

The speaker's rule (mind-to-meaning version): Utter "that" in such a way that 
in light of the circumstances the hearer can figure out what you intended to refer to in uttering it.

If the speaker's intention determines what the reference is, then, since hearers have an obligation to try to interpret correctly, they would have an obligation to determine the speaker's intention; so the speaker's obligation to facilitate the hearer's meeting of the hearer's obligation becomes the obligation to obey this rule for speakers.

Off hand, the mind-to-meaning version of the hearer's rule seems to call for an intellectually more challenging act of understanding on the part of the hearer than the meaning-to-mind version does, since the mind-to-meaning version calls on the hearer to contemplate the speaker's unobservable mental state. Someone might question whether the mind-to-meaning version is really more challenging than the meaning-to-mind version on the grounds that no positive account of the reference of demonstratives alternative to the speaker-intention theory has been set out so that a fair comparison might be made. For this reason, I will not contend that the mind-tomeaning version of the hearer's rule really is more psychologically demanding that the meaning-to-mind version of the hearer's rule.

But it is hard to make any excuses for the mind-to-meaning version of the speaker's rule. It is implausible that speakers regularly contemplate the question, "What will the hearer take me to be intending to refer to if I say 'that' in such-andsuch a way under such-and-such circumstances?" and then adjust their speech behavior in light of the answer that they come up with to this question. I, for one, am seldom, if ever, aware of doing that. If I seriously asked myself what another person would think about my intentions to refer, I do not know how I would go about answering the question. Sometimes I might recognize that I need to do something extra in order to enable hearers to grasp the reference of my utterance of a demonstrative (such as point with my finger), but that is still very far from my thinking about what the hearer will think that I intend to refer to. I do not assume that I can have such intentions only if I am aware, or conscious, of them, but my inability to become aware of them even when I try is at least a good reason to doubt that I have such intentions. It is much more plausible that speakers conceive of themselves as trying, for a given object of potential reference, to utter "that" in such a way, under such circumstances, that it really does refer to that object. There is no excuse for the mind-to-meaning version of the speaker's rule in the fact that the rules need not be consciously or deliberately obeyed. In order to be able to follow this rule in any sense at all, the speaker has to be differentially sensitive to the hearer's thoughts about the speaker's intentions, and that is already a steep challenge for the speaker.

To this it might be said that the mind-to-meaning version of the speaker's rule only looks more psychologically demanding than the meaning-to-mind version because the meaning-to-mind version has been mischaracterized. What it should be is, rather, this:

The speaker's rule (meaning-to-mind version), version 2: Utter "that" in such way that in light of the circumstances the hearer can figure out what the utterance refers to. 
On this version, the speaker still has to think about the hearer's thought process, but the speaker does not have to think about the hearer's thought about the speaker's intention. My reply is, first, that it is not clear why this rather than the other should be the meaning-to-mind version of the speaker's rule. If the hearer is supposed to make a meaning-to-mind inference, then the speaker just has to speak in such a way that an utterance of "that" really does refer to $o$, as the first version of the meaningto-mind version of the speaker's rule says, and then can rely on the hearer, as a competent speaker of the language, to understand what it refers to. And second, even if the speaker does in this way have to think about the hearer, this can still be a psychologically less demanding thought process than one in which the speaker has to think about the hearer's thoughts about the speaker's own intentions. It can be just a process of thinking about what the hearer will take the reference of the utterance of the demonstrative to be. I say that it can be, pending further development of a positive alternative, which I will not attempt here.

One might try to support general skepticism toward the mind-to-meaning version of the speaker's rule by appeal to the case of young children. Young children learn to use demonstratives competently before they master the attribution of mental states such as beliefs, desires and intentions. ${ }^{8}$ So they apparently cannot be following the mind-to-meaning version of the speaker's rule. Some psychologists are inclined to infer from so-called early false belief paradigms that children are able to attribute mental states at a much earlier age. I cannot take up the issue here, but I think we should view these conclusions with skepticism. ${ }^{9}$ Very young children may be sensitive to another person's direction of attention and goal-directed behavior, but it is extremely implausible that they are able to think thoughts to the effect that " $\mathrm{X}$ believes that I intended to refer to the toy in uttering 'that'," which is the kind of thought the mind-to-meaning version of the speaker's rule would call for. In any case, I do not want to rest my skepticism toward the mind-to-meaning version of the speaker's rule on the case of young children. Even if young children cannot obey this rule, it would be open to a proponent of the speaker-intention theory to claim that those young children are also not full-fledged speakers of the language. They will be full-fledged speakers of the language, it may be said, only once they have learned to make mind-to-meaning inferences.

A defender of the speaker-intention theory might defend it against my objection as follows: Yes, on the speaker-intention theory interlocutors must be guided in some sense by the mind-to-meaning versions of the hearer's and the speaker's rules. But the hearer can be guided well enough by the mind-to-meaning version of the hearer's rule, though he or she does not usually think about the speaker's referential intention at all, and the speaker can be guided well enough by the mind-to-meaning version of the speaker's rule, though he or she does not think about what the hearer will think about his or her referential. Hearers, it may be granted, normally identify the reference of an utterance of a demonstrative by relying on simple heuristics. These heuristics may include the assumption that the referent is the salient object

\footnotetext{
${ }^{8}$ For the age threshold for attribution of false belief, see Wellman et al. (2001). For the assumption that children competently employ demonstratives at an earlier age, I am relying on common experience.

${ }^{9}$ For a review of the issue, see de Bruin and Newen (2014).
} 
directly pointed at, or the assumption that the referent is the same as the referent of the most recently uttered definite, or the assumption that the speaker is referring to the thing about which it would make the most sense to say what the speaker says. Nonetheless, it is still true that hearers are guided, down deep, by the mind-tomeaning version of the hearer's rule, and that fact shows up when the simple heuristics are lacking or point in the wrong direction. In that case hearers often do switch, it might be said, to thinking about the speaker's intention.

Accordingly, it might be said, speakers may normally assume that hearers are relying on simple heuristics. They choose their words in such a way that hearers will normally identify the reference correctly if they rely on those simple heuristics. But one can still maintain that speakers are being guided by the mind-to-meaning version of the speaker's rule. That they are being so guided shows up in unusual cases. When the simple heuristics will not lead the hearer to the right conclusion, so that the hearer can be counted on not to rely on them, the speaker will contemplate the inferences that the hearer will make concerning the speaker's referential intention.

I can accept as much of this defense as pertains to the hearer. Yes, even if the hearer is still in some sense aiming to discover the speaker's referential intention, the hearer can do that by means of reliable inferential shortcuts that obviate all thought of the speaker's state of mind. But I do not accept the part of this defense that pertains to the speaker. If hearers do not normally think about speakers' referential intentions, and consequently speakers do not normally expect hearers to think about their referential intentions, but, rather, positively expect hearers to rely on other methods and consequently shape their speech behavior in light of that fact, then I do not see any sense in claiming that speakers are nonetheless being guided by the mind-to-meaning version of the speaker's rule.

The claim two paragraphs back was that speakers' conformity to the mind-tomeaning version of the speaker's rule shows up in unusual cases, when it is clear to the speaker that the hearer is not relying on the simple heuristics. But that claim really is not credible. Suppose, with the defender of the speaker-intention theory, that there really are the requisite simple heuristics. The case in which the speaker recognizes that the hearer will not be able to rely on these simple heuristics will be the case in which speaker recognizes that his or her speech, if executed according to plan, is not cooperative enough to allow the hearer to rely on the simple heuristics. In that case, the proper response for the speaker is to change course and speak in such a way that the hearer can rely on the simple heuristics. The only case in which the hearer will have to deviate from the simple heuristics and think about the speaker's intention will be the case in which the speaker failed to anticipate that the hearer would not be able to rely on the simple heuristics. But in that case the speaker still expects the hearer to rely on the simple heuristics. So there is not any clear case in which the speaker falls back on the mind-to-meaning version of the speaker's rule. 


\section{Demonstratives in thought}

If I look at a box of persimmons, some ripe, some not, I can direct my attention to one of them, the one in the lower left-hand corner, and think That is ripe! My thought itself contains an occurrence of a demonstrative, which refers to the persimmon in the lower left-hand corner of the box. Or so one might suppose. But if the speaker-intention theory is correct, then that cannot be right. According to that theory, if my thought really contains an occurrence of a demonstrative, then what it refers to can only be what I intend that occurrence to refer to. So the thought That is ripe! would have to be accompanied by another thought - an intention - to the effect that the occurrence of a demonstrative in the first thought refers to the persimmon in the lower left-hand corner. But that is absurd. So the speakerintention theory is mistaken.

This argument assumes that thoughts do contain demonstratives. In saying that a thought contains a demonstrative, what I mean is that the thought, considered as a representation in some kind of representational medium, contains a demonstrative. For example, if there is a language of thought, then it contains demonstratives. I am not assuming that the representational medium is entirely language-like, but I am also not assuming that it is distinct from the languages we speak. In any case, I am not talking about the propositional content of the thought. We can think of that propositional content in various ways, but whatever it is, it does not contain demonstratives (unless perhaps it is the content of a thought about a demonstrative).

An advocate of the speaker-intention theory might reply that the only demonstratives that we need in thought are demonstratives analogous to "I" and "now". The thought that I express with the words "That is ripe!" might be just the thought that the persimmon in the lower left-hand corner of the box in front of me now is ripe. This solves the problem, because for the first person and reference to the present time, we do not need anything like the speaker-intention theory, because demonstratives of this kind conform to a definite rule. "I" always refers to the speaker. "Now" always refers to the time of utterance. Even if that is not quite true for the demonstratives of spoken language, we can suppose it is true for the demonstratives that occur in thought that refer to the self and the present time. The reason we need a speaker-intention theory for a demonstrative like "that", it might be said, is precisely that there is no such strict rule by which the reference is determined; we need to fill in the gap by appeal to the speaker's intention.

Still, it is not very plausible that for every thought that we express with a demonstrative we can find another expression that would express that very same thought using at most the rule-governed kind of demonstrative. For example, if I look at the box of persimmons and exclaim, with reference to the one in the lower left-hand corner, "That is ripe!", then there need not be any particular description that is the content of the part of the thought that I express with "that". We might suppose that the thought I express is something like the thought that the persimmon in the lower left-hand corner of the box in front of me now is ripe, but it is not obvious that in my thought I have picked out some particular category of thing, such as persimmon or fruit or orange globe, to subsume it under. I can think, regarding 
the persimmon in the lower left-hand corner, that it is ripe without thinking of it as a persimmon, because I may not know what kind of fruit it is. I can see its color and the shape of its facing surface, but I need not have conceived of any general categories of colors and shapes such that I think of the color and the shape of this object as an instantiation of those categories. Even if I do have a description in mind of the object that the thought I express with a demonstrative refers to, that description may not in fact describe the object that the thought expressed refers to. The object that my thought refers to and that I think of as a persimmon may in fact be a plastic replica of a persimmon. In that case, the thought expressed with the sentence "That is ripe" cannot be the thought that the persimmon is ripe. ${ }^{10}$

Some people, I find, find it hard to conceive how there could be demonstratives in thought unless those demonstratives were somehow backed up by a description in the same thinker's thought of the thing referred to. They are disposed to ask, "How could a thinker know what he or she was thinking about unless he or she could describe it to him- or herself as the thing that uniquely satisfies some conditions?" In order to fully answer this question, I would need to put forward an alternative theory of demonstrative reference, which is beyond the scope of this paper. However, I would like to indicate that there are ways in which a reference may be secured for a demonstrative in thought other than by means of the thinker's uniquely describing it to him- or herself.

For example, what establishes the reference of a demonstrative in thought may be just the relevance to what the thinker is doing in having the thought. If the thinker is feeding horses and pouring just the right amount of oats from a sack into each bucket and at some point, while pouring oats into one of the buckets, thinks "That's enough", then it may be just the fact that this thought causes her to stop pouring that determines that the demonstrative in her thought refers to the oats in the bucket. In other cases, what establishes the reference relation between a demonstrative thought and the thing it refers to may be an associated mental image. What determines that the demonstrative in the thought That is ripe! refers to the persimmon in the lower left is that the demonstrative in thought is accompanied by a perception or a mental image of precisely that persimmon. ${ }^{11}$

At this point a defender of the speaker-intention theory might say the following: Whatever you can say to explain what makes it the case that a certain object is the reference of a mental demonstrative, I can say the same and then use the speakerintention theory to explain what makes it the case that a certain object is the reference of a spoken demonstrative. The trouble with this reply is that the accounts we can give of the relation between a demonstrative in thought and its reference threaten to put the speaker-intention theory of spoken demonstratives out of business. Just as the determinant of a demonstrative in thought can be what the speaker is doing in having the thought, so too the determinant of a demonstrative in

${ }^{10}$ Doubts along these lines could also be turned against Kaplan's theory of demonstratives (1989). According to Kaplan's preferred theory (in the "Afterthoughts" in his 1989), a demonstrative refers only by virtue of a description that the speaker has in mind. What I am questioning here is whether there is always a suitable description.

11 For further discussion of the ways in which "incomplete" thoughts may acquire a definite content, see Gauker (2013). 
speech can be what the speaker is doing in speaking. Just as the determinant of a demonstrative in thought can be an associated perceptual representation, so too the determinant of a demonstrative in speech can be the perceivable situation in which the act of speech occurs. If we don't need the speaker-intention theory to account for the reference of demonstratives in thought, then we do not need it to account for the reference of spoken demonstratives either. ${ }^{12}$

There remains perhaps one way out for the advocate of the speaker-intention theory. It's a two-stage strategy. At the first stage, one argues that, of those thoughts that we express with demonstratives, they are all either (a) thoughts whose contents we can express just as well without demonstratives (other than the strictly rulegoverned kind) or (b) thoughts about objects that we perceive. At the second stage, one argues that in the case of the thoughts that are about objects that we perceive, the perceptual representations are themselves components of the thoughts expressed. The thoughts that we took to be thoughts that contain demonstratives, it might be said, do not in fact contain demonstratives but in fact contain mental images, or perceptual representations, where we might have taken them to contain demonstratives. ${ }^{13}$ This is not a theory that, as I put it, threatens to put the speakerintention theory out of business, since spoken demonstratives cannot be replaced by perceptual representations.

It is plainly not obvious that the first stage of this strategy can succeed, but even if it can, it will still be doubtful whether the second stage can succeed. The nature of perceptual representation is a major topic in its own right, which I cannot take up here. Here I can do no more than point to a reason to doubt that imagistic representations can take the place of demonstratives in thought, namely, that imagistic representations do not seem to represent the kinds of thing that singular terms represent. A singular term (whether a demonstrative, name, or even a definite description) frequently represents a temporally persistent particular, such as a piece of fruit (of course, singular terms can represent other kinds of things too, for instance, universals such as triangularity). The object of reference is typically a thing that persists through time. Thus, if I think "That is not in the box" and a moment later think "That is in the box", it may make sense for me to go on to think, "That was not but now is in the box". It is not obvious that an imagistic representation likewise represents a persistent particular. For instance, if two images of a single persimmon represent different appearances of the persimmon (e.g. from different perspectives), it is not obvious that it makes sense to write, or think, an identity sign between the two images. A sequence of perceptions can certainly track the motions of an object as it moves around, even if it passes behind occlusions

\footnotetext{
12 For this reason, an account of mental demonstratives in thought such as Levine's (2010) will not necessarily support the speaker-intention theory of spoken demonstratives. According to Levine, a mental demonstrative is associated with a perceptual representation, and the object of that percept is the referent of the demonstrative. An objection is that not all mental demonstratives are associated with particular perceptions in the necessary way. But quite apart from that, to the extent that the theory works for mental demonstratives, it provides an alternative to the speaker-intention theory of spoken demonstratives.

13 See, for example, the account of so-called perceptual demonstratives in Raftopoulos and Müller (2006). On their account, perceptual representations may be demonstrative in the sense that they do not refer by means of a descriptive content.
} 
(Scholl and Pylyshyn 1999) or undergoes certain changes in appearance (Pylyshyn 2003 , p. 232), but it is not obvious that this tracking can be represented as a series of thoughts of the form $x=y$. For this reason it seems doubtful that an image can itself be the component of a thought that corresponds to a demonstrative in its verbal expression.

In doubting that mental images can be the components of thoughts that spoken demonstratives express, I do not mean to deny that mental images might have a place in a psychological account of the use of demonstratives. A perception, or even an endogenously generated mental image, may be precisely that which elicits an utterance of a sentence containing a demonstrative. We may understand the demonstratives of others in part by forming mental images of the things they are referring to. But to say all that is not yet to say that mental images (whether perceptual or concocted in imagination) can themselves be the components of thought that refer to the things that our spoken demonstratives refer to.

So there is one reply to the present objection (that thoughts contain demonstratives) that I have not fully countered. Nonetheless, I take this third objection to challenge the speaker-intention theory to at least the following extent. I have shown that a proponent of the speaker-intention theory has a commitment that he or she might not at first have recognized. The commitment is to explaining how there can be thoughts that are properly expressed with spoken demonstratives, though the thoughts themselves do not themselves contain demonstratives.

\section{The dirty fork revisited}

At the start, I told a story in which I gesture and look at the fork in front of me, while intending to refer to the fork to my left, and utter, "That is dirty!" The speakerintention theory holds that the reference of my utterance of the demonstrative "that" can only be the fork to my left; if it is not that, then my utterance of a demonstrative has no reference at all. But the speaker-intention theory, I have argued, is mistaken. So we are free, as far as that goes, to say that my utterance of a demonstrative referred to the fork in front of me. My utterance of "That is dirty!" was literally false. My utterance literally said, of the fork in front of me, that it was dirty. That is not to say that what I or other people care about most will also be what my utterance literally said. What I and they most care about may be, rather, what I was really thinking. But what a person's utterance literally says is normally the same as what he or she was really thinking, and so there is that secondary reason to take an interest in what my utterance literally said as well.

Acknowledgements Open access funding provided by Paris Lodron University of Salzburg. Versions of this paper were presented at the conference "Conceptual Thought and Linguistic Communication" in Salzburg, May 2016, at the conference "What is Said / What is Meant" in Berlin, September 2016, and at the University of Milan, February 2018. I thank the audiences on those occasions, an anonymous reviewer for this journal and Graeme Forbes, in his capacity as an editor, for their comments and questions.

Open Access This article is distributed under the terms of the Creative Commons Attribution 4.0 International License (http://creativecommons.org/licenses/by/4.0/), which permits unrestricted use, 
distribution, and reproduction in any medium, provided you give appropriate credit to the original author(s) and the source, provide a link to the Creative Commons license, and indicate if changes were made.

\section{References}

Åkerman, J. (2015). The communication desideratum and theories of indexical reference. Mind and Language, 30, 474-499.

De Bruin, L. C., \& Newen, A. (2014). The developmental paradox of false belief understanding: A dualsystem solution. Synthese, 191, 297-320.

Gauker, C. (2008). Zero tolerance for pragmatics. Synthese, 165, 359-371.

Gauker, C. (2010). Global domains versus hidden indexicals. Journal of Semantics, 27, 243-247.

Gauker, C. (2012). What Tipper is ready for: A semantics for incomplete predicates. Noûs, 46, 61-85.

Gauker, C. (2013). Inexplicit thoughts. In L. Goldstein (Ed.), Brevity (pp. 74-90). Oxford: Oxford University Press.

Gauker, C. (2015). How many bare demonstratives are there in English? Linguistics and Philosophy, 37, 291-314.

Heck, R. G., Jr. (2014). Semantics and context-dependence: Towards a Strawsonian account. In A. Burgess \& B. Sherman (Eds.), Metasemantics: New essays on the foundation of meaning (pp. 327-364). Oxford: Oxford University Press.

Kaplan, D. (1989). Demonstratives: An essay on the semantics, logic, metaphysics, and epistemology of demonstratives and other indexicals. In J. Almog, J. Perry, \& H. Wettstein (Eds.), Themes from Kaplan (pp. 481-564). Oxford: Oxford University Press.

King, J. C. (2014). Speaker intentions in context. Nô̂s, 48, 219-237.

Larson, R. K., \& Segal, G. M. A. (1995). Knowledge of meaning: An introduction to semantic theory. Cambridge, MA: MIT Press.

Levine, J. (2010). Demonstrative thought. Mind and Language, 25, 169-195.

Lewerentz, L., \& Marschall, B. (2018). Metasemantics, intentions and circularity. Synthese, 195, $1667-1679$.

Pylyshyn, Z. (2003). Seeing and visualizing: It's not what you think. Cambridge, MA: MIT Press.

Raftopoulos, A., \& Müller, V. C. (2006). Nonconceptual demonstrative reference. Philosophy and Phenomenological Research, 72, 251-285.

Scholl, B., \& Pylyshyn, Z. (1999). Tracking multiple items through occlusion: Clues to visual objecthood. Cognitive Psychology, 38, 258-290.

Speaks, J. (2016). The role of speaker and hearer in the character of demonstratives. Mind, 125, 301-339.

Speaks, J. (2017). A puzzle about demonstratives and semantic competence. Philosophical Studies, 174, 709-734.

Stokke, A. (2010). Intention-sensitive semantics. Synthese, 175, 383-404.

Wellman, H. M., Cross, D., \& Watson, J. (2001). Meta-analysis of theory-of-mind development: The truth about false belief. Child Development, 72, 655-684.

Wettstein, H. (1984). How to bridge the gap between meaning and reference. Synthese, 58, 63-84. 